\title{
VIOLÊNCIA, MEMÓRIA E NOVAS GRAMÁTICAS DA RESISTÊNCIA: O DESASTRE DA SAMARCO NO RIO DOCE
}

\section{VIOLENCE, MEMORY AND NEW FORMS OF RESISTANCE: THE SAMARCO DISASTER IN THE RIO DOCE}

\author{
Andréa Zhouri*
}

\begin{abstract}
Essa casa aqui, eu era noivo, eu trabalhei uns dois anos fora daqui...cortava lenha lá de machado, pra construir...tentar fazer minha casa. Ai eu consegui fazer minha casa e casei. Depois que eu fiz a casa, casei, tive meus filhos todos aqui, 8 filhos...Ai veio a lama e destruiu todos os sonhos que nós tinha aqui foi destruido [...] (Getúlio, morador de Paracatu de Baixo, abril de 2017)

Depois que eu lutei tanto, meu Deus... Dei tantas enxadada, trabalhei tanto pra mim lutar pra fazer minha casa. E aqui tudo era porcelanato, tá tudo atolado aí, oh! Nem acabei de pagar. Tô pagando ainda, porque eu peguei um dinheiro emprestado pra mim comprar [...] Banheiro, esse lado aqui óh, eu fiz recente. Telhado, tudo tinha feito novo. Ai eu casquei a casa toda e reboquei tudo, bem rebocado. Cê vê que nem cair não caiu, né? (Consuelo, moradora de Paracatu de Baixo, abril de 2017) ${ }^{1}$
\end{abstract}

\section{Introdução ${ }^{2}$}

Caminhando pelos escombros de Paracatu de Baixo - comunidade rural destruída pela avalanche de rejeitos minerais liberados pelo rompimento da barragem de Fundão, em Mariana, Minas Gerais, ${ }^{3}$ moradores juntam os cacos da memória e reconstroem

\footnotetext{
* Professora do Departamento de Sociologia e Antropologia da Universidade Federal de Minas Gerais UFMG - (Belo Horizonte/MG/Brasil). Doutora em Sociologia. E-mail: azhouri@gmail.com

1. Depoimentos coletados durante atividade de cartografia comunitária realizada com moradores de Paracatu de Baixo em abril de 2017 no âmbito do projeto de pesquisa: O Desastre e a Política das Afetações: compreensão e mobilização em um contexto de crise, realizado com apoio FAPEMIG/CAPES. Os nomes dos moradores de Paracatu de Baixo são ficcionais, enquanto os nomes dos moradores de Bento Rodrigues que aparecem na última parte deste texto são reais, tal como aparecem no vídeo intitulado Do desastre $\dot{a}$ resistência: peregrinações em defesa do lugar. Disponivel em https://www.youtube.com/watch?v=VeMKCDyprF4. Acesso em 27 de maio de 2018.

2. Agradeço ao Conselho Nacional de Desenvolvimento Científico e Tecnológico (CNPq) e à Fundação de Amparo à Pesquisa do Estado de Minas Gerais (FAPEMIG) pelo apoio às pesquisas que fomentam esta reflexão. A bolsa de Estágio Senior da Coordenação de Aperfeiçoamento de Pessoal em Nível Superior (CAPES) possibilitou a elaboração do texto, incluindo a participação no Seminário Mining in comparative perspective: trends, transformations and theories, Ghent, Belgium, 13-14 December 2017, entre outras atividades realizadas na Universidade de Kassel e Universidade Livre de Berlim durante o ano de 2017.

3. Para outras análises sobre o desastre do Rio Doce, ocorrido em 5 de novembro de 2015, consultar textos reunidos no dossiê Mining, Violence and Resistance, Vibrant, v.14. n. 2, 2017. Disponível em http://www. vibrant.org.br/issues/lastest-issue-v-14-n-2-05-082017/, acesso em 27 de maio de 2018.
} 
por meio dela, de maneira vívida e precisa, a espaço-temporalidade de suas casas, da vila e, sobretudo, das relações sociais que permitem compreender as formas de organização social e produtiva que teciam a vida na localidade (Appadurai, 2004), incluindo nela o sítio camponês (WOORTMAN, 1983). ${ }^{4}$

Aqui eu plantava o inhame chinês, milho, mandioca, feijão, alface, couve, cebolinha, repolho, tomate das duas qualidades (grande e o pequeno), um pé de limão, pé de laranja cravo, mexerica cravo, um pé de uva, um pé de jabuticaba, mexerica poncã e o tal de pé de manga, eu acho que existe ainda. Eu tinha a minha [horta], a Ana tinha a dela. Eu compartilhava com a Ana assim: talvez na casa de Ana tinha acerola e eu não tinha, na casa de Vilma tem acerola e eu não tinha. Aí eu plantava mandioca, na casa de Ana não tinha, Ana tinha aquele negócio, carambola e eu não tinha... (Inácia)

Ah, tudo aqui era vizinho, praticamente é família. [...] aqui tudo é de meu pai e minha mãe. E aí nós foi casando e Getúlio meu irmão ali, eu aqui. João meu cunhado ali, que hoje ele já morreu. Aí a Aurora e Vanda que é ali em cima, que é minha irmã. Lá, naquele cantinho, são os primos, que mora lá naquelas casas, último do canto lá. As casas quebradas era também. Zilda minha irmã na frente ali, quase tudo família aqui. (João)
Minha esposa trabalhava picado aí pros outros, um dia pra um, um dia pra outro, andou trabalhando pra Renata por muito tempo ali, por dia. Trabalhava em outros lugar também aí. E nossa vida aqui na roça era assim, girando direto. Ela plantava milho, capinava milho, rancava feijão, fazia de tudo, qualquer serviço. E hoje, inclusive hoje, com a gente lá em Mariana, ela não adapta em cidade. (Getúlio)

A expressão "girando direto" é significativa de um modo de vida tradicional que inclui mulheres fazendo a horta e plantando o alimento da "dispensa" (a comida certeira, que provém dos cultivos no quintal), que também é "girado" na troca com vizinhos e parentes em um sistema de reciprocidade próprio à vida camponesa. Homens - e mulheres muitas vezes - "giram" ainda na capina da roça, no cuidado com animais, na construção de casas, cercas e outras benfeitorias, trocando os dias de trabalho com vizinhos ou vendendo o dia para os que podem pagá-lo. Assim, a violência do desastre solapou vidas e eliminou, de forma irreparável para muitos moradores, fatores preponderantes ao modelo de organização do trabalho agrícola: o aproveitamento das potencialidades ecológicas locais e a complementariedade das unidades produtivas que compunham essa paisagem, também centrada nas relações de parentesco, de gênero e de reciprocidade entre vizinhos (WOORTMAN e WOORTMAN,

4. Os depoimentos dos moradores nos informam sobre a lógica organizacional do sítio camponês no distrito de Mariana, Minas Gerais, e nos permitem identifica-lo com o modelo analisado por Woortman (1983) em suas pesquisas no estado de Sergipe. Segundo a autora, o sítio camponês se configura como um sistema de espaços diversificados, complementares e articulados entre si. Esse sistema organizacional esta informado por uma lógica, uma estratégica e um know how que possibilitam a reprodução da produção camponesa e da vida na localidade. E é nesse sentido que se apresenta o horizonte das perdas retratado pelos atingidos durante as oficinas realizadas em 2017. 
2004). 0 comprometimento das estratégias de vida (OLIVER-SMITH, 1993; BEBBINGTON, 2011) entrelaça passado, presente e o futuro agora incerto das comunidades.

A violência material, simbólica e epistêmica observada no território apresenta-se como um dos efeitos derrame da mineração (GUDYNAS, 2016), os quais também se estendem espacial e temporalmente para fora da localidade e implicam em transformações políticas, econômicas e institucionais em diferentes escalas. Neste sentido, a abordagem exige observar o princípio heurístico da variação de escalas (REVEL, 2010) para o objetivo de se compreender e relacionar processos políticos e econômicos tramados fora da localidade, em circuitos transnacionais e nacionais de poder (WOLF, 2003) que, por sua vez indigenizados, retornam à localidade reproduzindo violências históricas em novos e inusitados formatos.

Por certo, o tema da violência no Brasil é recorrente na historiografia e na sociologia sobre o país desde o período colonial e está presente na vida cotidiana dos brasileiros do campo e da cidade, com evidente componente racial, conforme relatório do Instituto de Pesquisa Econômica Aplicada - IPEA (CERQUEIRA, 2017). Desnaturalizar a violência é entender as formas atuais por meio das quais ela se apresenta e se intensifica, tarefa que desafia constantemente a compreensão sobre o Brasil e a luta pela construção de uma sociedade mais justa, digna e diversa. Sem a pretensão de ser exaustiva, nos limites deste texto pretendo refletir, a partir do desastre do Rio Doce, algumas formas de produção da violência em torno de práticas institucionais e políticas que fazem o neoextrativismo possível (ARAÓZ, 2013). Desta forma, aponto para desdobramentos tais como: revisão das leis e desmanche das instituições de proteção ambiental e cuidado com os direitos indígenas, quilombolas e povos tradicionais; deslocamento da política para a polícia, sinalizando as estratégias de criminalização de movimentos sociais, lideranças, assessoria e até mesmo pesquisadores por parte de grupos transnacionais extrativos e do Estado; e, para finalizar, apresento algumas gramáticas da resistência que, ao atualizarem elementos da tradicionalidade, como as celebrações próprias do catolicismo popular, colocam-se de forma autônoma e além dos modelos convencionais e burocratizados de atuação política sob disciplinamento do Estado e do mercado. Para fazer esta análise, trago aportes que acionam variação de escalas que entrelaçam processos globais, nacionais e locais ao tempo em que registro elementos etnográficos em ocorrência nos territórios.

\section{Economia global, desregulação e novas zonas de sacrifício}

Uma onda extrativa em larga escala marca a primeira década do novo milênio no Brasil, estando associada a um processo mais amplo de re-primarização da economia que envolveu indistintamente governos conservadores e os ditos progressistas na América Latina. Esse 'consenso das commodities' (SVAMPA, 2013) que ocorre no âmbito de um modelo econômico neoextrativista (GUDYNAS, 2016) reforçou a posição subordinada dos países latinoamericanos na economia global. A partir dos anos 2000, empresas mineradoras, principalmente as de ferro, intensificaram suas operações com vistas a aumentar a escala de produção, simultaneamente reduzindo os custos fixos. Novas 'zonas de sacrifício' foram abertas nesse processo, quer dizer, novas fronteiras econômicas em torno da mineração vem avançando ferozmente sobre os territórios dos povos indígenas e das comunidades tradicionais. 
Nesse processo, as mineradoras contam com o suporte do Estado em suas diferentes instâncias - executivo, legislativo e judiciário - o que nos permite perceber o escopo dos 'efeitos derrame' da mineração para além das consequências sociais e ambientais. A governança socioambiental erigida entre os anos 1980 e 1990, por exemplo, sofre processo gradual de erosão. Esta tendência se acelera a partir de 2011, quando se inicia uma queda na demanda intermacional por minério. ${ }^{5}$ Entre os efeitos estão a queda na arrecadação dos municípios, nas taxas teoricamente pagas a título de compensação aos danos ambientais, aumento das ameaças de desastres e de acidentes de trabalho, falhas no monitoramento e no controle ambiental dos projetos. As estratégias das corporações e do Estado insistem na monopolização e na privatização dos ambientes comuns, principalmente os territórios dos povos indígenas, das comunidades tradicionais e do campesinato de forma geral, algo que configura enorme pressão sobre florestas, terras, solos, rios e subsolo (ZHOURI; BOLADOS; CASTRO, 2016). 0 avanço sobre as terras tradicionalmente ocupadas tem provocado conflitos, inclusive com a destruição de comunidades rurais inteiras, como revela o desastre ocorrido no Vale do Rio Doce.

Em novembro de 2015, o colapso da barragem de rejeitos da empresa Samarco, uma joint venture de duas gigantes da mineração internacional, Vale e BHP Billiton, promoveu o maior desastre da mineração (em volume de rejeitos) da América Latina. Foram dezenove mortes imediatas e milhares de pessoas deslocadas, que enfrentam a perda de suas casas, terra, plantações e criações. Os desalojados foram obrigados a viver temporariamente em casas alugadas na cidade, enredados em negociações diárias e até hoje inconclusas, submetidos a uma espera angustiante pelo reassentamento e incertezas sobre o futuro (ZHOURI et al., 2017; LOSEKANN, 2017). De súbito, dezenas de cidades se viram com problemas de abastecimento de água, enquanto a lama mineral se extendia por $600 \mathrm{~km}$ até o oceano Atlântico. Os efeitos são continuados e se multiplicam, enquanto as falhas no processo de licenciamento ambiental, no monitoramento e na fiscalização da barragem são conhecidas, conforme aprofundam as reflexões de Santos e Milanez (2017).

5. Entre 2011 e 2014, o volume de exportação mineral do Brasil caiu de US\$ 44.2 bilhões para US\$ 28.4 bilhões (International Trade Center 2016). Considerando minério de ferro, cobre e alumínio, os três principais minerais de exportação do país, os preços por tonelada tiveram declínio de 41\%, 20\% e 20\%, respectivamente (World Bank 2016). 


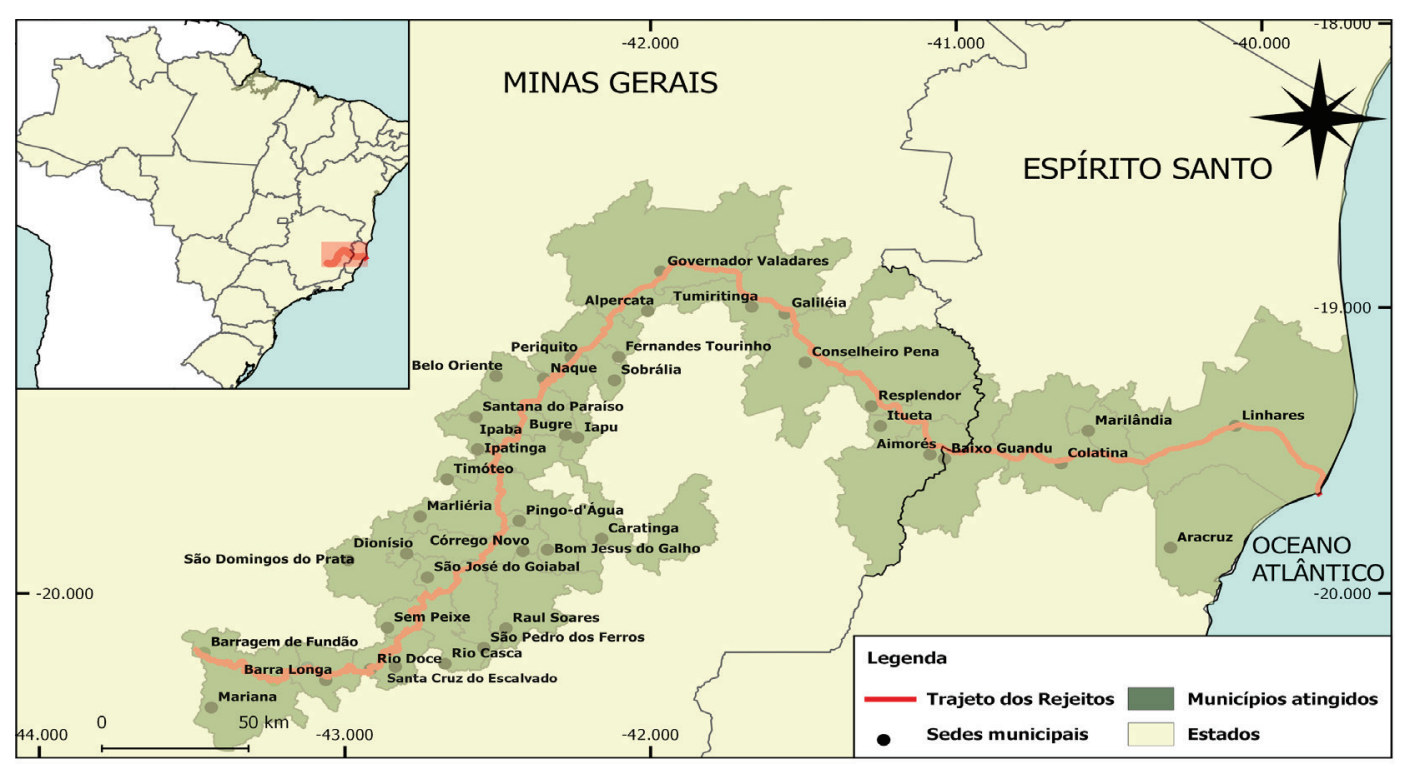

Figura 1 - Trajeto dos rejeitos da Barragem de Fundão desde o município de Mariana, estado de Minas Gerais, até a sua foz no Oceano Atlântico, no estado do Espírito Santo. Elaborado por Max Vasconcelos, 2017.

De forma significativa, importa lembrar que logo após a ruptura da barragem, parlamentares da Assembléia Legislativa de Minas Gerais (ALMG) não hesitaram em aprovar um decreto que flexibiliza o licenciamento ambiental para torná-lo mais célere na aprovação de licenças para a mineração. Processo semelhante ocorreu no Senado Federal, em que uma proposta de Ementa Constitucional, introduzida anteriormente, em 2012, foi aprovada no início de 2016. $\mathrm{Na}$ prática, essas manobras representam o desmantelamento do sistema de normas que obriga a avaliação de impacto ambiental para o licenciamento das grandes obras (ZHOURI et al., 2017; ACSELRAD, 2017).
Em agosto de 2017, com a intenção de dar início à exploração mineral em uma área entre os estados do Pará e do Amapá, o governo federal publicou um decreto para a extinção da Reserva Nacional de Cobre e seus Associados (RENCA). Trata-se de uma área de $46.000 \mathrm{~km} 2$, criada em 1984, e que abriga em seu interior um total de nove áreas protegidas: duas Terras Indígenas e sete Unidades de Conservação, sendo três de proteção integral e quatro de uso sustentável. Alguns meses antes, uma portaria do Ministério de Minas e Energia, ${ }^{6}$ procurou regulamentar as outorgas e os títulos minerais vigentes naquela área. ${ }^{7}$ Essas iniciativas fazem parte de um contexto

6. MME No. 128, de 30 de março de 2017.

7. Na ocasião, o diretor-geral do Departamento Nacional de Pesquisa Mineral (DNPM) informou a imprensa sobre o aumento significativo de requerimentos para concessão de títulos minerais na Reserva, desde a sua criação, sinalizando o "interesse do Mercado nessas áreas” (http://www.valor.com.br/brasil/4934205/ apos-30-anos-extracao-de-ouro-pode-voltar-amazonia). Acesso em 11/04/2017. 
mais amplo para reaquecimento do setor minero-extrativo, que contam ainda com o lançamento do Programa de Revitalização Mineral Brasileira em julho de 2017 e três Medidas Provisórias (MPs 789, 790 e 791) que versam sobre a criação da Agência $\mathrm{Na-}$ cional de Mineração - ANM, a modificação do Código de Mineração e a revisão da legislação que trata da Compensação Financeira pela Exploração de Recursos Minerais - CFEM. $^{8}$

A flexibilização das normas e o retrocesso institucional colocam em questão a própria noção de democracia e confıguram um dos efeitos derrame da mineração. A desregulação socioambiental em curso tem sido acompanhada por variadas formas de violência, as quais caminham lado a lado com processos que visam a despolitização e a criminalização de atingidos, movimentos e grupos engajados na resistência à mineração, além de pesquisadores críticos.

Da política para a polícia: violência institucionalizada e criminalização

0 processo de desregulação ambiental, que já vinha ocorrendo gradualmente desde o início dos anos 2000, encontrou seu ápice no governo Michel Temer, que assume o poder em 2016, após o polêmico processo de impeachment da presidente eleita Dilma Roussef. A título de ilustração, alguns fatos ocorridos no primeiro semestre de 2017 permitem associar a força política da aliança entre setores do agronegócio e da mineração no poder ao incremento da violência no campo e nas florestas. Em uma de suas primeiras manifestações públicas após nomeação, o ministro da justiça, parlamentar da bancada ruralista no congresso nacional, declarou: "Vamos parar com essa discussão sobre terra para índios. Terra não enche barriga de ninguém...O que importa é lhes dar boas condições de vida" (Osmar Serraglio. Folha, 10 de março de 2017). Sua passagem pelo ministério da justiça do governo pós-impeachment foi curta, mas o suficiente para que em três meses o país assistisse a retrocessos no que tange a observação dos direitos constitucionais indígenas. Como congressista, o ministro havia sido o relator da Proposta de Ementa Constitucional (PEC 215) que objetiva mudar as normas de demarcação das terras indígenas, transferindo o poder do executivo para o legislativo nesta matéria, entre outras estratégias que propiciem a atividade minerária em terras indígenas.

Nesse mesmo período, o presidente da bancada ruralista no congresso (Nilson Leitão, do PSDB-MT), levou adiante a Comissão Parlamentar de Inquérito (CPI) da Fundação Nacional do Índio (FUNAI) e do Instituto Brasileiro de Colonização e Reforma Agrária (INCRA). Esta CPI acabou por indiciar uma centena de pessoas, incluindo dezenas de antropólogos, procuradores, agentes governamentais e ONGs, por alegada fraude nas demarcações de terras indígenas.

As investidas governamentais e parlamentares contra os direitos indígenas e

8. Vide carta de repúdio assinada pela Associação Brasileira de Antropologia e outras 22 associações científicas enviadas à Presidência da República em http://www.portal.abant.org.br/index.php/2-uncategorised/1222-carta-de-repudio-a-extincao-da-renca, acesso em 29/09/2017. 
quilombolas não apenas fomentam a criminalização de movimentos sociais, lideranças comunitárias, ONGs e pesquisadores envolvidos com as temáticas agrárias e indígenas no Brasil, mas abrem espaço para a escalada de violência nos territórios. 0 número de assassinatos de camponeses e indígenas em 2017 registrou aumento vertiginoso. De acordo com o relatório anual sobre conflitos no campo da Comissão Pastoral da Terra (CEDOC - Dom Thomás Balduíno, CPT 2018), 71 pessoas foram assassinadas em conflitos no campo em 2017, um aumento em relação a 2015 e 2016, anos em que tiveram ocorrência de 50 e 61 casos, respectivamente. Os atentados cresceram de 74 para 120 ocorrências e as ameaças de morte tiveram um aumento de 200 casos em 2016 para 226 . $^{9}$ 0 lado mais terrivel desses assssinatos são os masacres: cinco no total, com 31 vítimas. Vale mencionar três casos sequenciais ocorridos nos primeiros cinco meses do ano: em dezenove de abril, dez camponeses, incluindo crianças, foram assassinados e torturados no distrito rural de Colniza, noroeste de Mato Grosso. Poucos dias depois, em trinta de abril, um grupo de fazendeiros armados com rifles e machetes atacou um assentamento de cerca de quatrocentas famílias do povo Gamela, no estado do Maranhão. 0 Conselho Indigenista Missionário (CIMI) reportou então o ferimento de vinte indígenas, incluindo crianças. Muitos foram atirados pelas costas e tiveram suas mãos decepadas. No mês seguinte, em vinte e quatro de maio, houve o massacre de Pau D'Arco, no Pará, quando dez camponeses foram brutalmente assassinados.

Um outro relatório, publicado pela Global Witness (2017), documentou 200 assassinatos de defensores ambientais e agrários em 24 países no ano de 2016, com destaque para aqueles relacionados à mineração. Mais de 60\% desses assassinatos ocorreram na América Latina, sendo que o Brasil lidera em número absoluto de mortes. Em nível nacional, o relatório publicado pela Comissão Pastoral da Terra (CPT), Conflitos no Campo 2016, mostra que 43,6\% dos 172 casos de conflito por água no Brasil durante 2016 ocorreram nos estados de Minas Gerais e Espírito Santo. Mais de 50\% do total estão relacionados aos conflitos envolvendo projetos de mineração, seguidos de 23,26\% relativos a barragens hidroelétricas (CPT, 2017, p. 129-130). Em Minas Gerais, onze lideranças comunitárias de diferentes regiões do estado, consideradas representantes de atingidos por projetos de mineração, estão inseridos no Programa de Proteção aos Defensores de Direitos Humanos. ${ }^{10}$ No âmbito do complexo minerário Minas-Rio, de propriedade da empresa Anglo American, o expediente do interdito proibitório tem sido utilizado pela empresa para silenciar as vozes de dissenso, ou as

9. Para detalhes, consultar, CEDOC Dom Tomás Balduino - CPT, 2018 in www.cptnacional.org.br .

10. Vide reportagem em 0 Tempo, 10 de julho de 2017, disponível em http://www.otempo.com.br/ capa/economia/conflitos-de-minera $\% C 3 \% A 7 \% C 3 \% A 30-l e v a m-11$-a-programas-de-prote $\% C 3 \% A 7 \%-$ C3\%A3o-1.1495202. Acesso em 31 de julho de 2017. Para uma análise sobre a criminalização de atingidos no projeto Minas-Rio, da empresa Anglo American e o adoecimento dos moradores atingidos a jusante da barragem de rejeitos, consultar Prates (2017). 
que simplesmente protestam pelos seus direitos violados (PRATES, 2017). ${ }^{11}$

Ainda na primeira metade de 2017, uma carta aberta assinada por dezenas de organizações e pesquisadores denunciaram a administração Temer por retrocessos sem precedentes do sistema de proteção do meio ambiente, povos indígenas e trabalhadores rurais. Além das medidas legislativas que pretendem retirar os direitos dos indígenas às terras onde tradicionalmente vivem, e que são reconhecidos pela Constituição do Brasil e por acordos internacionais assinados pelo país, como a Convenção 169 da OIT, o ataque incluiu também um corte de 55\% no orçamento da FUNAI e a nomeação de um general para presidir o órgão. ${ }^{12}$

As mudanças institucionais e normativas desautorizam a interpretação da violência como decorrente de meras falhas institucionais e/ou da governança. Ao contrário, elas demandam análises que reflitam sobre o papel do Estado na promoção das variadas formas de violência, incluindo até mesmo aquelas geradas pela produção de tecnologias de gestão de conflitos ambientais forjadas no âmbito de espaços globalizados de poder.
Indigenização da governança ambiental breve recapitulação

Seja a propósito do projeto de mineração Minas-Rio, seja no caso do desastre do Rio Doce, já tivemos a oportunidade de argumentar sobre modalidades distintas de violência impostas por tecnologias de resolução de conflitos ambientais empregadas por empresas e pelo Estado (ZHOURI, 2014 e ZHOURI et al., 2017, respectivamente). As pesquisas mostram que as mesmas tecnologias de resolução de conflitos utilizadas no licenciamento ambiental de grandes obras tem sido equivocadamente mobilizadas para o caso do desastre do Rio Doce. Tais tecnologias revelam um panorama que envolve a articulação/aliança entre corporações financeiras, operações extrativas que congregam capital intensivo, intensivos/ extensivos recursos naturais, velhas elites fundiárias, assim como o moderno agronegócio. Não é demais lembrar que esta foi a mesma aliança que sustentou os governos anteriores, ditos progressistas, pavimentando o caminho para o contexto crônico que se agrava atualmente.

De fato, na última década, um conjunto de normas e leis vem sendo revistas no Bra-

11. Para a continuidade desse panorama em 2018, ver "Death threats against critics of Anglo American's Minas-Rio project in Brazil”, publicado pela London Mining Network em 7 de maio de 2018. Disponível em http://londonminingnetwork.org/2018/05/death-threats-against-critics-of-anglo-americans-minas-rio-project-in-brazil/, consultado em 27 de maio de 2018.

12. Funcionários do ICMBio escrevem sobre exoneração de servidores técnicos de carreira e a efetivação de interventores políticos e empresariais em unidades regionais do órgão encarregado do cuidado com as unidades de conservação e os programas de proteção das espécies da fauna e da flora brasileiras. Blog de Rogério Rocco, disponível em http://rogeriorocco.blogspot.de/2017/10/nomeacoes-de-interventores-politicos-e.html?m=1. Acesso em 18 de outubro de 2017. 
sil, a exemplo do código florestal, código das águas e o código da mineração. As tentativas de rever a constituição de 1988 não são recentes, sobretudo no que concerne a demarcação de terras indígenas. 0 mesmo pode ser dito do sistema de regulação ambiental. Tampouco é recente o processo de criminalização do dissenso, especialmnente da crítica à implementação dos grandes empreendimentos (ZHOURI; e OLIVEIRA, 2007; GIFFONI, 2012).

Ao longo dos anos, na verdade, o sistema ambiental foi se tornando cada vez mais permissivo aos projetos degradadores do meio ambiente (CARNEIRO, 2005), apesar de formalmente aderirem a certos princípios do pacote da governança ambiental internacional (relatórios técnicos, audiências públicas, conselhos participativos). As medidas mitigadoras e de compensação ambiental foram paulatinamente substituindo análises de viabilidade ambiental dos empreendimentos, permitindo a execução de projetos por meio de suas legalizações através de continuadas condicionalidades (ZHOURI, 2014). A hidrelétrica de Belo Monte na Amazônia é o exemplo paradigmático: licenças ambientais foram concedidas com centenas de condicionantes até hoje não cumpridas na sua integralidade. 0 mesmo pode ser dito sobre o mega-mineroduto da empresa Anglo American, que liga Minas Gerais ao Rio de Janeiro. ${ }^{13}$ As análises da realidade socioambiental dos grupos atingidos e, por conseguinte, os seus direitos, ficam a reboque do interesse na implementação e operação dos projetos.

Um dos principais e mais polêmicos aspectos do licenciamento ambiental refere-se ao dimensionamento da área ou do universo atingido. Em geral, na perspectiva do licenciamento, prevalece o ponto de vista do empreendimento, a despeito das condições e processos socioecológicos existentes nos lugares. Neste sentido, a área atingida é sempre aquela coincidente com as estruturas dos projetos, ou seja, o reservatório, no caso das hidrelétricas, as minas e barragens de rejeitos, no caso da mineração, entre outras estruturas necessárias às obras em ambos os casos (casa de força, canteiro de obras, pilhas de estéril etc.).

A mesma lógica rege os procedimentos, em negociação, para identificação dos atingidos no contexto do desastre do Rio Doce. A defınição do universo dos atingidos tem circunscrito esses últimos às localidades/ propriedades que coincidem com o percurso/perímetro da lama, ou seja, a calha da lama, e não à vida organizada socialmente nos lugares. Assim, definições sobre situações envolvendo deslocamento físico e deslocamento econômico, por exemplo, a partir de diretrizes do Banco Mundial (IFC 2012), funcionam como procedimentos de inclusão/exclusão para adequação financeira das reparações aos interesses das empresas envolvidas (ZHOURI et al., 2017). A miopia estratégica das empresas e do Estado (Scott 1998) torna as comunidades enquan-

13. 0 Minas-Rio é um complexo minerário que inclui a exploração de minério de ferro a céu aberto em Minas Gerais, um sistema de transporte via ductos (mineroduto) que percorrem $529 \mathrm{Km}$ de extensão, cortando 33 municípios, e um porto no litoral do Rio de Janeiro (ver ZHOURI, 2014 e SANTOS et al., 2017) 
to tais - suas formas de organização social e produtiva - invisíveis. A padronização do tecido social surge como mecanismo de gestão dos custos e controle dos sujeitos e dos seus territórios (SCOTT, 1998).

A violência simbólica que determina inclusões e exclusões, se manifesta pelo fetichismo dos números cadastrais (ZHOURI et al., 2017) e categorias administrativas como impacto e externalidade ambiental, as quais elidem de fato aquilo que na realidade se apresenta: a expropriação e consequente aniquilação de um modo de vida. Essa violência simbólica e material esta alinhada à violência institucional que muda as normas e marcos regulatórios, que estabelece a política de deslocamentos forçados em que ocorrem a violação de direitos humanos, notadamente, o direito à informação, o direito à água potável, ao ir e vir, à alimentação, entre outros (PRATES, 2017).

Outro pilar da governança ambiental global presente no licenciamento ambiental é erigido sob a premissa da participação, cuja indigenização no Brasil e em Minas Gerais possibilita traçar caminhos que levam da aceitação ao silenciamento. Quando o paradigma do desenvolvimento sustentável aterriza no Brasil nos idos de 1980, o requisito da participação logo dialogou positivamente com os anseios por democracia no país. Contudo, a prática ao longo dos anos foi reproduzindo circuitos de poder característicos da sociedade, onde apenas certos grupos e sujeitos sociais se habilitam às formas de participação desenhadas globalmente. A participação em espaços burocratizados, onde as pessoas dominam um certo léxico, uma certa gramática política, administrativa e até mesmo técnica, celebra o discurso competente (CHAUÍ, 2008 [1983]) enquanto desqualifica, silencia e exclui outras maneiras de expressão políti- ca. No entanto, o dissenso e as diversas formas de manifestação política se manifestam em cenários de conflitos, contrariando a ideologia da harmonia que subjaz na concepção de desenvolvimento sustentável.

Povos indígenas, pescadores, camponeses, quilombolas entre outros se mobilizam para contestar o ataque aos seus territórios. As experiências críticas revelam que os múltiplos processos das violências das afetações promovidas pelos agentes da mineração em larga escala fazem emergir contextos de lutas e de resistência que entrecruzam distintas trajetórias de ativistas, grupos atingidos, militantes e pesquisadores (RIGOTTO, 2017; ZHOURI; GENEROSO; CORUJO, 2016), assim como inusitadas formas de manifestação política, como as peregrinações de retorno às comunidades destruídas organizadas por grupos de atingidos pelo desastre do Rio Doce.

\section{Reconstruindo subjetividades: peregrinações em defesa do lugar}

Desde o rompimento da barragem, os moradores de Bento Rodrigues, distrito rural imediatamente destruído pela lama da Samarco - maneira como os atingidos se referem ao desastre - foram levados para a cidade de Mariana e, após breve abrigo no ginásio de esportes, foram alojados em diferentes hotéis da cidade. Na sequência, casas foram alugadas de forma a acomodar as famílias temporariamente. Os moradores, dispersos pela cidade, nunca deixaram de visitar a vila destruída, a despeito das interdições colocadas, em distintos momentos, pela defesa civil, o judiciário e a própria empresa, que viria a construir um dique no terreno, para indignação dos moradores.

A cada visita, as lembranças sofridas do ocorrido se mesclavam aos relatos emocio- 
nados sobre a vida na comunidade, as descrições pormenorizadas das casas, quintais, bens, relações sociais e sonhos perdidos. Narrar e chorar a perda era ritual importante frente à experiência traumática que os colocava em uma situação de vulnerabilidade. Era como se o ato de contar o drama, pessoal e da coletividade, ajudasse a elaborar emocionalmente as perdas e resgatar subjetividades soterradas: "Em três minutos eu perdi 43 anos da minha vida”, repetia seu Zé Barbosa em uma das primeiras visitas de retorno, enquanto seus olhos vagavam pelo terreno, como a identificar os traços da sua história entre os vestígios do seu lugar de pertença. Aos poucos, as peregrinações individuais foram assumindo formas mais coletivas e ritualizadas, como na celebração das festas religiosas que sempre reuniam a comunidade em datas fixadas pelo calendário religioso católico.

Uma das primeiras celebrações foi a festa de Nossa Senhora das Mercês, realizada nos dias 24 e 25 de setembro de 2016, por iniciativa de um grupo denominado 'Loucos por Bento'. Os moradores fizeram um cortejo pelas 'ruas' abertas entre os destroços da comunidade, rumo à igreja que sobreviveu à lama por localizar-se numa parte mais alta da vila. À frente, os festeiros carregavam a bandeira, seguidos pelo pároco e seus assistentes, moradores e a banda de música.

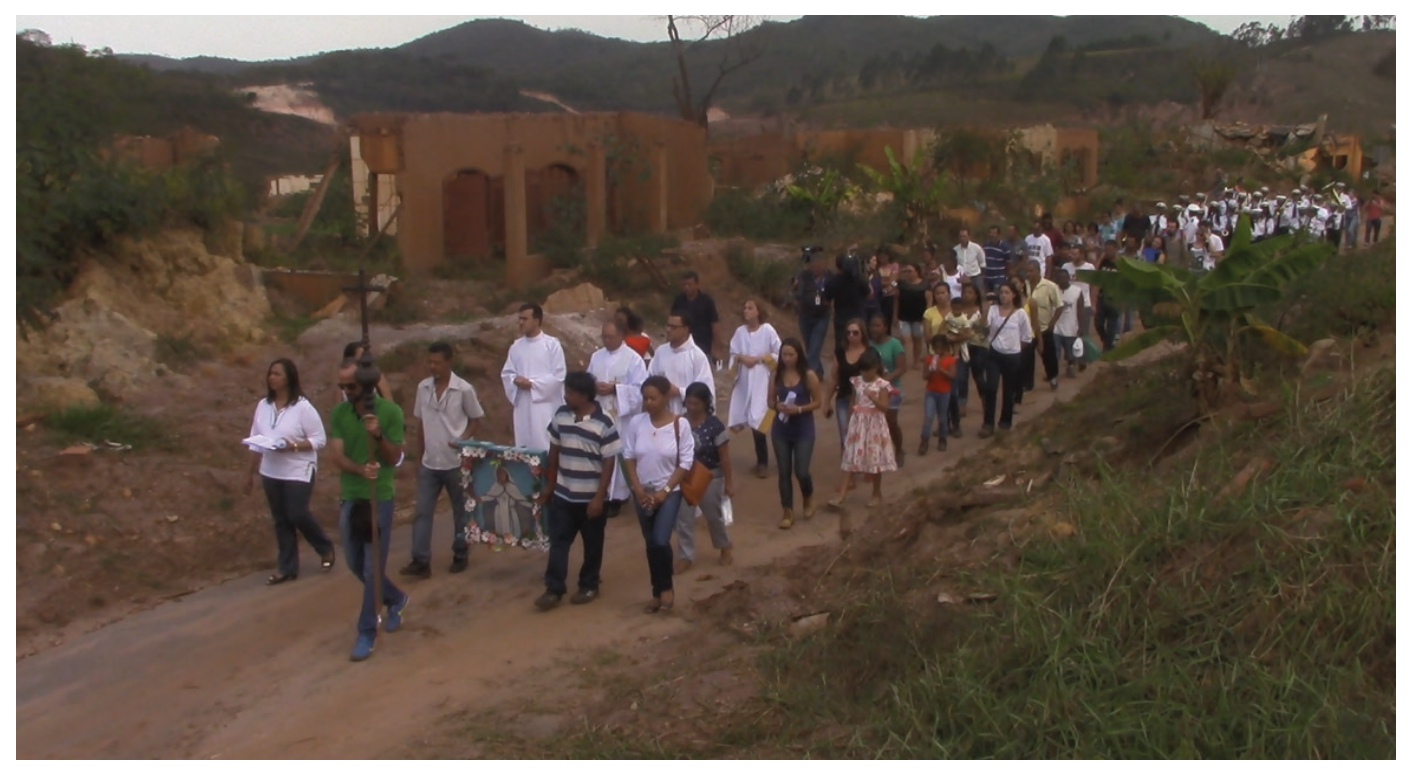

Procissão de Nossa Senhora das Mercês, em 24 de Setembro de 2016, Bento Rodrigues Fonte: GESTA-UFMG 


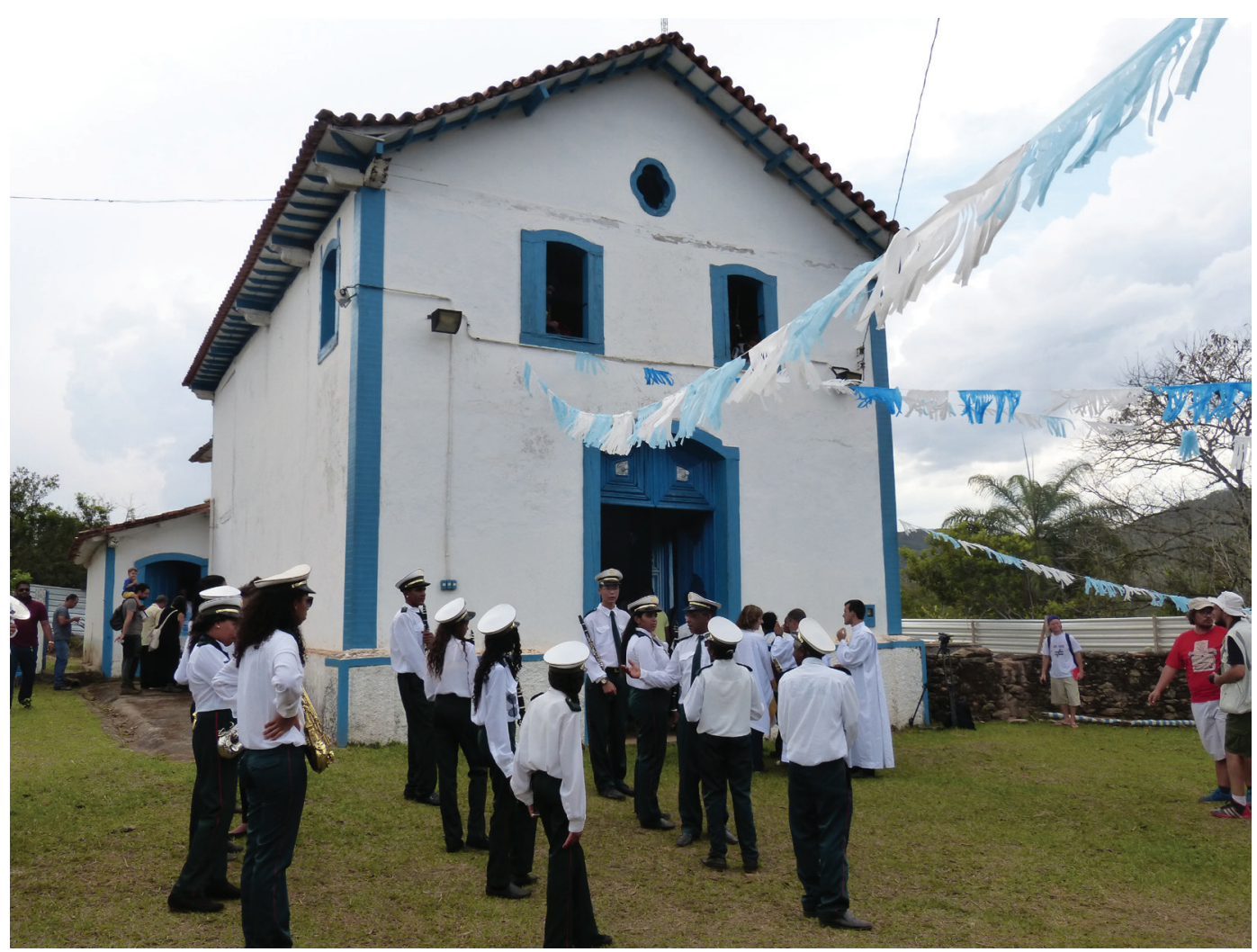

Procissão de Nossa Senhora das Mercês, em 24 de Setembro de 2016, Bento Rodrigues Fonte: GESTA-UFMG

Na igreja, após a missa, houve hasteamento do mastro e da bandeira, queima de fogos e oferta de lanche aos presentes. Tudo muito rápido nesta parte, uma vez que havia ameaça de chuvas e os agentes das empresas monitoravam de perto a movimentação, lembrando aos presentes que havia horário determinado em juízo para a permanência no lugar. Em depoimento para um pequeno filme que registraria a festa, ${ }^{14}$ o morador Marcos comenta:

Uma das grandes recordações, nessa igreja de Nossa Senhora da Mercês é uma refor- ma que meu pai, o senhor Neto, Manoel Muniz, fez... Eu era 6 pra 7 anos, então eu lembro muito, porque a maneira de chegar água aqui pra construção, eu achava o máximo, era de charrete, era com cavalo. Então eu e meus irmãos e outras pessoas né... isso é o máximo e traz muita lembrança. E mesmo que a Samarco vem falando em fazer o [dique] S4, isso é uma...a gente não pode deixar gente, porque vai acabar nossas memórias aqui, entendeu!? Mesmo do jeito que tá aí, nós temos que continuar vindo pra cá, que seja chorar.

14. Filme Do desastre à resistência: peregrinações em defesa do lugar. Disponível em https://www.youtube.com/watch?v=VeMKCDyprF4\&t=53s. Acessado em 18 de outubro de 2017. 
No jogo entre o lembrar e o esquecer (POLLACK, 1989), a memória aciona identidades, oferece substrato às subjetividades, individuais e coletivas, reafirmando o lugar do sujeito no mundo, ao tempo em que permite organizar novas narrativas, sensibilidades e sentidos, como a indignação frente às pretensões da empresa em relação à construção de um novo dique no terreno da comunidade.

No retorno à cidade, uma carreata de moradores parou na estrada, em um ponto onde há uma nascente d'água muito apreciada. De forma animada, eles festejavam o sucesso das celebrações e recordaram a forma como a festa acontecia no passado.

A Nossa Senhora das Mercês antes, no sábado, tinha a procissão da bandeira saindo da casa de um festeiro, mas era a noite. Sete horas a gente saia pra procissão, subia, ia pras Mercês, chegava lá tinha a missa... o hasteamento da bandeira. Quando a gente descia, a gente não podia descer direto não, porque Seu Raimundo tava na porta e era aniversário dele. Assim, a gente passava lá no Seu Raimundo, jantava, comia sobremesa. A banda parava e tocava... homenageava ele.
Aí, depois disso, ia pra praça e tinha o som na praça até de madrugada.

Até de manhã cedo. A gente deitava um pouquinho, cochilava, tinha a alvorada com fogos e sinos, depois da alvorada a gente levantava e ia limpar a praça, varrer a praça. Aí depois tinha a retreta 3 horas, depois a procissão e a missa, encerrando com a benção do Santíssimo, isso era no domingo (Maria das Graças, moradora de Bento Rodrigues).

A memória das festas, organizadas pelos próprios moradores, resgata o sentido da autonomia perdida frente a um presente estranho e sob domínio alheio. Neste sentido, a realização das festas religiosas no contexto atual passou a compor uma espécie de gramática política em meio às lembranças do passado compartilhado, cuja projeção desde o presente, permite vislumbrar rumos para um futuro. Elas representam um momento de communitas (TURNER, 1991) em meio a um cotidiano agora dominado pela incerteza e pela espera, uma rotina burocratizada de reuniões e assembléias sob o disciplinamento do Estado e das empresas (ZHOURI; OLIVEIRA; ZUCARELLI; VASCONCELOS, 2017).

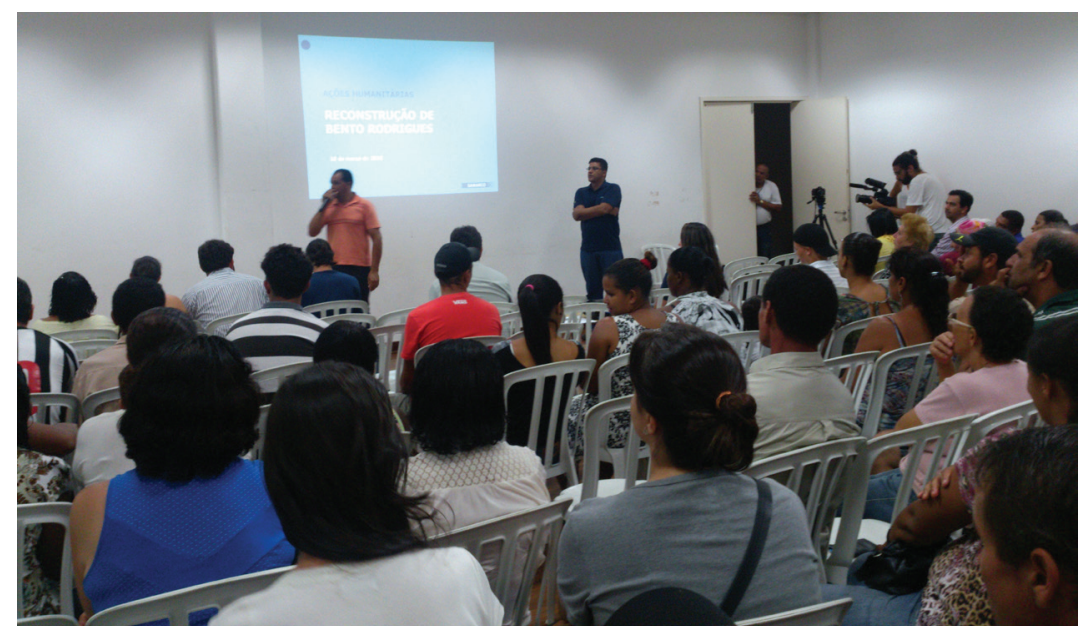

Reunião sobre reconstrução de Bento Rodrigues, 10 de março de 2016.

Fonte: Marcos Zucarelli. GESTA/UFMG 
Ao lembrarem de como haviam realizado a festa de São Bento na cidade de Mariana, após o rompimento da barragem, Maria das Graças e Mônica explicam:

- Aí a gente fez a de São Bento lá em Mariana, mas não foi...

- Não, não foi...

- eu chorei o tempo todo, porque não foi... Foi no dia de São Bento certinho, tudo bem, mas foi numa capela que não era a nossa, as imagens doadas pelos irmãos de São Paulo que doaram pra gente, mas fizemos procissão numas ruas que não eram a nossa. Todo mundo olhando a gente com umas caras... né!?

Porque a gente invadiu as ruas de Mariana e fizemos tudo numa coisa que não era nossa.

0 sentimento de estar deslocado, fora do seu lugar, assim como os indícios do preconceito sofrido na cidade sublinham o esforço para realização da festa no lugar onde se tem o sentimento de pertença, além de indicarem outros elementos de resistência, reforçados pela narrativa sobre obstáculos que teriam sido colocados pela empresa às iniciativas dos moradores:

Aí no dia 30 o Mauro [morador] falou assim: Eu vou soltar uns foguetes lá no Bento. Nós falamos: você não vai sem a gente, ai fomos todo mundo.

Lá no Bento foi a nossa Festa. Nós chegamos lá umas 4 horas mais ou menos,

eles puseram um monte de pedras pra gente não passar. Levamos pessoas de 80, 80 e tantos anos. Aí quando foi quase seis horas a gente, no pé da igreja ali não tem aquela porteira? Ali tava fechado, não tinha como passar. Nós iniciamos a celebração ali, no escuro já, acendemos vela, lanterna, aí descemos pela rua até chegar em frente onde era a igreja de São Bento. Mas a gente desabafou, ali é da gente, ali é nosso, ali que é nosso.

0 reconhecimento do lugar “da gente” é também o encontro consigo e com a sua história. Outra moradora, Silmaria, reflete sobre as diferenças entre aquele dia para este:

A diferença desse dia pra hoje é porque hoje a gente entrou de cabeça erguida, com autorização. E assim, nós entramos, entramos no nosso lugar, com o nosso direito de volta. Hoje foi a nossa libertação mesmo. Aquele dia nós entramos escondido... entramos com medo, com medo de vir alguém, de impedir, de fazer alguma coisa. Hoje nós entramos no nosso lugar, com autorização.

Hoje nós celebramos pra mostrar pra eles que nós não vamos parar, que lá tem dono, que nós vamos brigar. Nós vamo brigar até o fim pra não virar uma barragem de rejeito.

A condição de liminaridade se revela ainda na experiência paradoxal que mescla autonomia e tutela: "o lugar é nosso, mas estou e não estou autorizada a nele entrar”. É preciso lembrar que naquele contexto, lutava-se para que o dique S4, pleiteado pela empresa Samarco, não fosse construído na área do que restou da comunidade. Entretanto, após embates envolvendo os atingidos, o ministério público e o judiciário, o governo de Minas Gerais acabou por autorizar a construção do dique, que alagou os terrenos dos moradores e áreas tombadas pelo Patrimônio Histórico. Os moradores se sentiram derrotados, novamente usurpados de suas terras, bens e lugar de pertença. Mas os rituais de peregrinação e de retorno ao lugar continuam, como momentos de communitas (TURNER, 1991) a reafirmar 
laços de solidariedade, reconhecimento de subjetividades e da coletividade, configurando expressão de uma gramática da resistência. São momentos de peregrinação em defesa do lugar que permitem acionar memórias, sociabilidades perdidas e/ou desestruturadas pelo desastre. São movimentos em defesa da subjetividade, da história e da autonomia, e configuram um discurso político que se manifesta para além das audiências públicas e reuniões institucionalizadas que teimam em disciplinar corpos, linguagem e mentes.

\section{Referências}

ACSELRAD, H. Mariana, November, 2015: the political genealogy of a disaster. Dossier Mining, Violence and Resistance, Vibrant, v. 14, n. 2, 2017. pp.149-158. Versão em português em ZHOURI A. (Org.) Mineração, Violências e resistências. Marabá, PA: iGuana; ABA, 2018. Disponivel em http://www.aba.abant.org.br/files/20180308 5aa16473d6197.pdf. Acesso em 27 de maio de 2018.

ARAÓZ, H. Orden neocolonial, extractivismo y ecología política de las emociones. In: RBSE Revista Brasileira de Sociologia da Emoção, v. 12, n. 34, pp. 11-43, Abril de 2013.

APPADURAI, A. “A produção da Localidade”. In: Dimensões Culturais da Globalização. Lisboa: editora Teorema, 2004. Pp. 237-263.

BEBBINGTON, A. Minería, movimientos sociales y respuestas campesinas: una ecología política de transformaciones territoriales. Lima: Instituto de Estudios Peruanos, 2011.

CERQUEIRA, D. Et al. Atlas da Violência no Brasil 2017. Rio de Janeiro: IPEA, junho de 2017.

CARNEIRO, E. J. A oligarquização da "política ambiental" mineira. In: ZHOURI, A.; LASCHEFSKI, K.; PEREIRA, D. (Org.). A Insustentável Leveza da Política Ambiental: desenvolvimento e conflitos sócio-ambientais. Belo Horizonte: Autêntica, 2005.

CHAUI, M. Cultura e democracia: o discurso competente e outras falas (11a. Edição). São Paulo: Cortez, pp.368, 2008.

IFC. INTERNATIONAL FINANCIAL CORPORATION. Handbook for Preparing a Resettlement Action Plan. Washington, DC: IFC, 2012.

GIFFONI, R. A pesquisa sobre conflitos ambientais e o assédio processual a pesquisadores no Brasil. In: Revista Antropolítica, n. 36, pp. 49-82, Niterói, 1. sem. 2014.

GLOBAL WITNESS, Defenders of the Earth, global killings of land and environment defenders in 2016. LONDRES. Disponivel em: https:// www.globalwitness.org/en/campaigns/environmental-activists/defenders-earth/. Acessado em: 17/10/2017.

GUDYNAS, E. Extractivismos en America der Sur: conceptos y sus efectos derrame. In: Zhouri A.; Bolados P.; Castro E. (Eds.). Mineração na America do Sul: neoextrativismo e lutas territoriais. São Paulo: Annablume. pp. 23-43, 2016.

INTERNATIONAL TRADE CENTER. Trade map: trade statistics for international business development. Available in: http://www.trademap.org. Access in 19 July, 2016.

LOSEKANN, C. "It was no accident!" The place of emotions in the mobilization of people affected by the collapse of Samarco's tailings dam in Brazil”. Dossier Mining, Violence and Resistance, Vibrant, v. 14, n. 2, 2017. pp. 102-126.Versão em português em Zhouri A. (Org.) Mineração, Violências e resistências. Marabá, PA: iGuana; ABA, 2018. Disponível em http://www.aba.abant.org.br/ files/20180308 5aa16473d6197.pdf. Acesso em 27 de maio de 2018.

OLIVER-SMITH, A. Post-Disaster Reconstruction: an overview of issues and problems. Paper presented at the Seminar on Socioeconomic Aspects of Disasters in Central America, San Jose, Costa Rica., 1993.Disponível em: <http://cidbimena.desastres.hn/pdf/eng/doc6405/doc6405-contenido. 
pdf>. Acesso em 18/02/2016

POLLAK, M. Memória, esquecimento e silêncio. Rio de Janeiro: Estudos Históricos, vol. 2, n. 3, p. 03-15, 1989.

PRATES, C. Efeitos Derrame da mineração, violências cotidianas e resistências em Conceição do Mato Dentro-MG. Dissertação de mestrado defendida no Programa de Pós-Graduação Sociedade, Ambiente e Território, UFMG-UNIMONTES, Montes Claros, 2017.

REVEL, J. Micro-história, macro-história: o que as variações de escala ajudam a pensar em um mundo globalizado. Revista Brasileira de Educação v. 15 n. 45 set./dez. 2010

RIGOTTO, R. Contested Knowledges in the Environmental Conflict over Uranium and Phosphate Mining in Ceará - Brazil. Dossier Mining, Violence and Resistance, Vibrant, v. 14, n. 2, 2017. pp.184-204. Versão em português em Zhouri A. (Org.) Mineração, Violências e resistências. Marabá, PA: iGuana; ABA, 2018. Disponivel em http://www.aba.abant.org.br/files/20180308 5aa16473d6197.pdf. Acesso em 27 de maio de 2018.

SANTOS, A. F.; FERREIRA, L; and PENNA, V. Supposed impacts, Real Violence: the construction of reality in the implementation of the Minas-Rio Project. Dossier Mining, Violence and Resistance, Vibrant, v. 14, n. 2, 2017. pp. 159-183. Versão em português em Zhouri A. (Org.) Mineração, Violências e resistências. Marabá, PA: iGuana; ABA, 2018. Disponivel em http://www.aba.abant. org.br/files/20180308_5aa16473d6197.pdf. Acesso em 27 de maio de 2018.

SANTOS, R; e MILANEZ, B. The construction of the disaster and the "privatization" of mining regulation: reflections on the tragedy of the Rio Doce Basin, Brazil". Dossier Mining, Violence and Resistance, Vibrant, v. 14, n. 2, 2017. pp. 127-146. Versão em português em Zhouri A. (Org.) Mineração, Violências e resistências. Marabá, PA: iGuana; ABA, 2018. Disponivel em http://www.aba.abant.org.br/files/20180308_5aa16473d6197.pdf. Acesso em 27 de maio de 2018.

SCOTT, J. Seeing Like a State: how certain schemes to improve human condition have failed. New Haven, London: Yale University Press, 1998. SCOTT, P. Negociações e Resistências Persistentes: agricultores e a barragem de Itaparica num contexto de descaso planejado. Recife: Editora UFPE, 2009.

SVAMPA, M. Consenso de los commodities y lenguajes de valoración en América Latina. Revista Nueva Sociedad, 244: 30-46, marzo-abril, 2013.

TURNER, V. The ritual process: structure and anti-structure. New York: Cornell University press, 1991 [1969].

WOLF, E. Encarando o poder: velhos insights, novas questões. In Feldman Bianco B.; Ribeiro G. L. (Org.) Antropologia e Poder: contribuições de Eric Wolf. Brasília: Editora Universidade de Brasilia; são Paulo: Imprensa Oficial do Estado de são Paulo; Ed. Unicamp, 2003. pp. 325-343.

WOORTMANN, E. O Sítio Camponês. Anuário Antropológico, 81: 164-203. Brasília: Editora Tempo Brasileiro, 1983. . E WOORTMANN, Klaas. 0 Tra-

balho da Terra: a lógica e a simbólica da lavoura camponesa. Brasília: Editora da UnB, 1997.

WORLD BANK. World Bank commodity price data. Washington: World Bank, 2016.

ZHOURI, A.; e OLIVEIRA, R. Desenvolvimento, conflitos sociais e violência no Brasil rural: o caso das usinas hidrelétricas. Revista Ambiente \& Sociedade [online]. 2007, vol.10, n.2, pp.119-135 ; GENEROSO, P.; CORUJO, T.

Nas tessituras da pesquisa e da ação: narrativas de mulheres sobre água, mineração, resistência e colaboração em Minas Gerais. In: Zhouri A.; Bolados P.; Castro E. (Eds.), Mineração na América do Sul: neoextrativismo e lutas territoriais. São Paulo: Annablume, 2016, pp. 341-367. .; BOLADOS, P.; CASTRO, E. Mineração na América do Sul: neoextrativismo e 
lutas territoriais. São Paulo: Annablume, 2016.

; OLIVEIRA, R.; ZUCARELLI,

M,; VASCONCELOS, M. The Rio Doce Mining Disaster in Brazil: between policies of reparation and the politics of affectations". In Dossier Mining, Violence and Resistance, Vibrant, v. 14, n. 2, 2017. Pp 81-101. Versão em português em Zhouri A. (Org.) Mineração, Violências e resistências. Marabá, PA: iGuana; ABA. Disponivel em http://www.aba.abant.org.br/files/20180308 5aa16473d6197.pdf. Acesso em 27 de maio de 2018. 
RESUMO

A partir do desastre da Samarco no Rio Doce, em curso desde 2015, o texto reflete sobre formas de produção da violência em torno de práticas institucionais e políticas que fazem o neoextrativismo possível no Brasil. Desta forma, aponta para processos como: revisão das leis e desmanche das instituições de proteção ambiental e cuidado com os direitos indígenas, quilombolas e povos tradicionais; deslocamento da política para a polícia, sinalizando as estratégias de criminalização de movimentos sociais, lideranças, mediadores e pesquisadores por parte de grupos transnacionais extrativos e do Estado. Por fim, apresenta novas gramáticas da resistência que, no caso específico, ao atualizarem elementos da tradicionalidade, como as celebrações próprias do catolicismo popular, colocam-se de forma autônoma em relação aos modelos convencionais e burocratizados de atuação política sob disciplinamento do Estado e do mercado. Para fazer esta análise, o texto aciona o princípio heurístico da variação de escalas que entrelaça processos globais, nacionais e locais na reprodução de violências históricas que, por outro lado, fazem emergir novos esforços de subjetivação nos territórios.

\section{PALAVRAS-CHAVES}

Desastre. Mineração. Violência. Resistência. Rio Doce

\section{ABSTRACT}

Based on the Samarco disaster, ongoing in the Rio Doce since 2015, the article reflects about forms of violence production around institutional and political practices that make neo-extractivism possible in Brazil. Thus, it points to processes such as the revision of laws and the dismantling of environmental protection institutions and agencies responsible for policies related to indigenous, quilombolas and traditional peoples rights; the displacement of politics to the police, signaling the strategies of criminalization of social movements, mediators and researchers by transnational extractive groups and the State. Finally, it presents new modalities of resistance that, in this ethnographic case, by updating elements of traditionality, such as the celebrations proper to popular Catholicism, stand for autonomy in face of the conventional models of political action under both market and State discipline. To make this analysis, the text triggers the heuristic principle of scale variation that intertwines global, national and local processes in the reproduction of historical patterns of violence that, on the other hand, give rise to new efforts of subjectivation in the territories.

\section{KEY-WORDS}

Disaster. Mining. Violence. Resistance. Rio Doce.

Recebido em: 18/06/2018

Aprovado em: 18/08/2018 